\title{
Erratum to: Al7050-T7451 turning simulation based on the modified power-law material model
}

\author{
Feng Jiang • Jianfeng Li $\cdot$ Jie Sun $\cdot$ Song Zhang • \\ Zhongqiu Wang $\cdot$ Lan Yan
}

Published online: 1 December 2009

(C) Springer-Verlag London Limited 2009

\section{Erratum to: Int J Adv Manuf Technol}

DOI 10.1007/s00170-009-2328-9

Unfortunately, an error occurred in Fig. 9.

The correct Fig. 9 is given below

The online version of the original article can be found under http://dx. doi.org/10.1007/s00170-009-2328-9.

F. Jiang $(\bowtie) \cdot J$. Li $\cdot$ J. Sun $\cdot$ S. Zhang $\cdot$ Z. Wang

Key Laboratory of High Efficiency and Clean Mechanical

Manufacture, Shandong University, Ministry of Education,

Jinan, China

e-mail: jiang.feng.sdu@gmail.com

L. Yan

College of Mechanical \& Vehicle Engineering, Hunan University,

Changsha, China

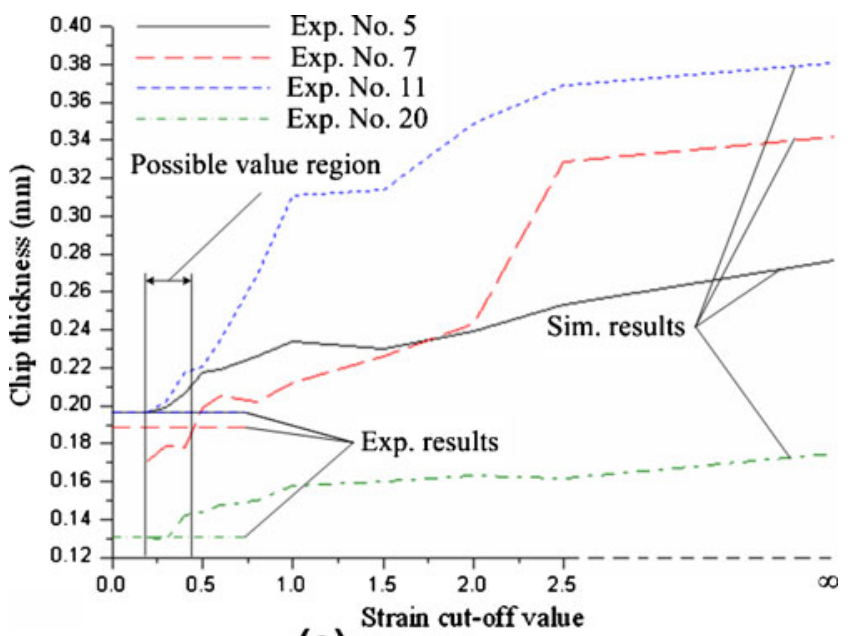

(a) Chip thickness

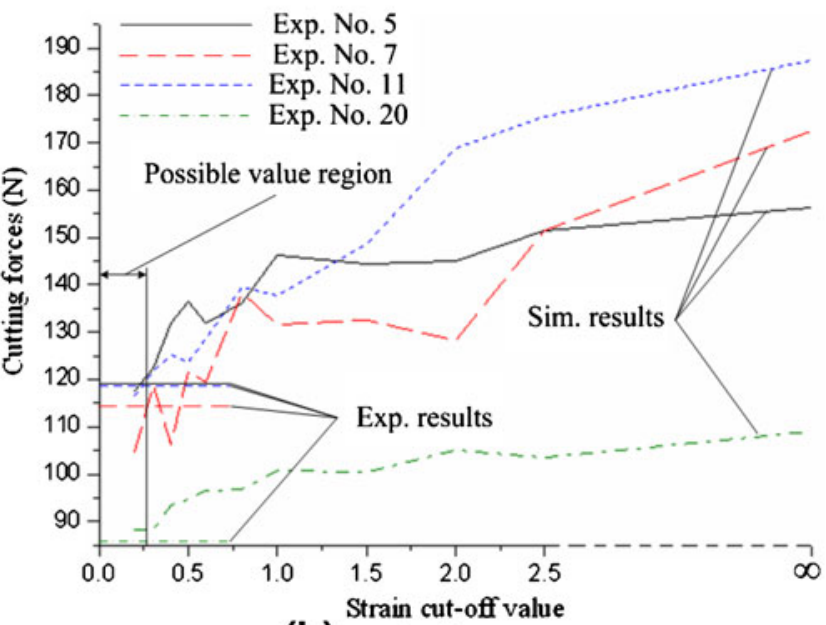

(b) cutting forces

L. Yan

Fig. 9 Determination of the strain cut-off value

Department of Mechanical Engineering,

Worcester Polytechnic Institute,

Worcester, MA, USA 